\title{
THE NORWEGIAN PRESIDENCY \\ 2017
}

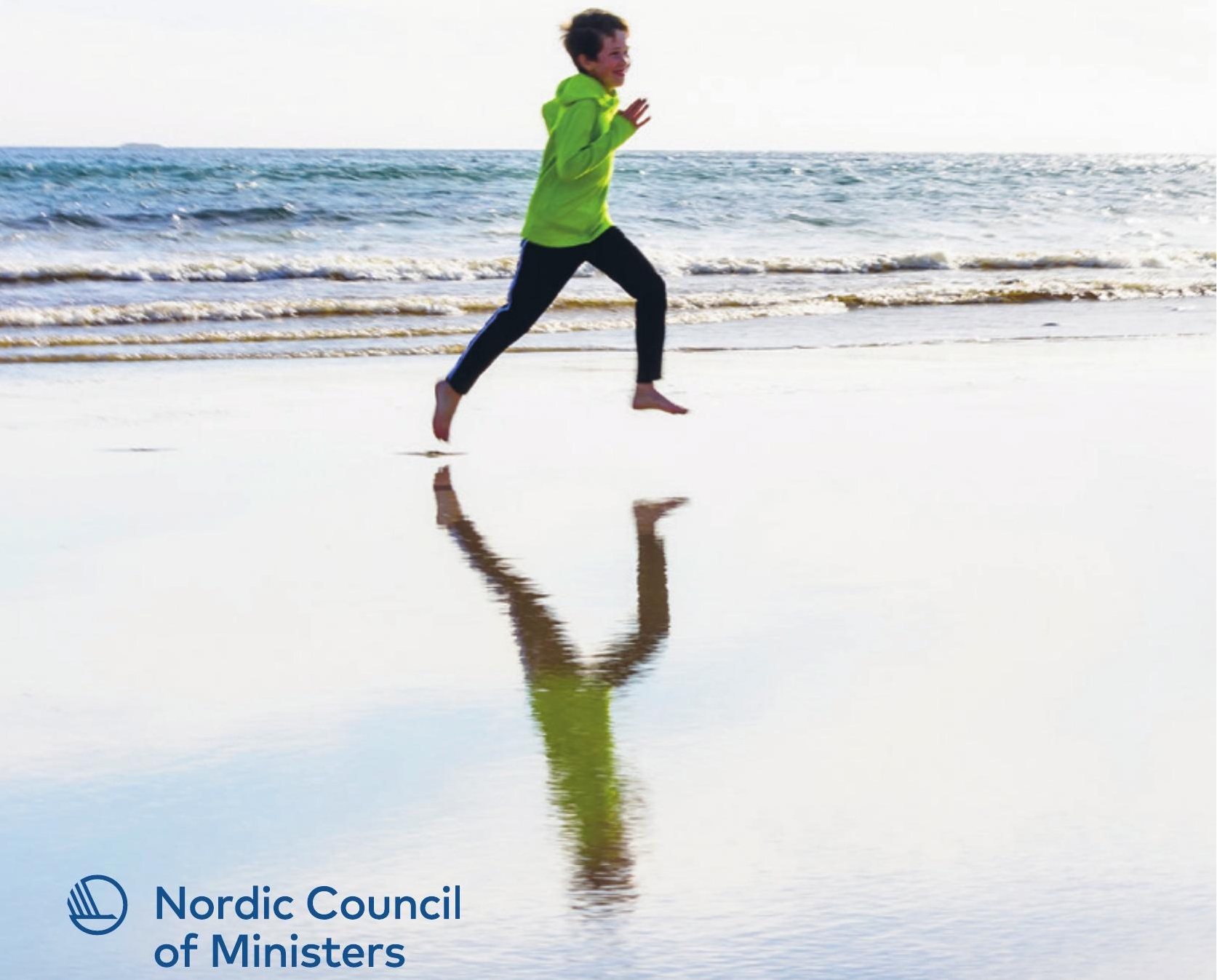


The Norwegian Presidency 2017

ISBN 978-92-893-4702-0 (PRINT)

ISBN 978-92-893-4703-7 (PDF)

http://dx.doi.org/10.6027/ANP2016-766

ANP 2016:766

(C) Nordic Council of Ministers 2016

Layout: Mette Agger Tang

Photos: Scanpix

Photo p. 4 top: Thomas Haugersveen/Office of the Prime Minister

Photo p. 4 bottom: Sturlason/Ministry of Foreign Affairs

Print: 07-gruppen

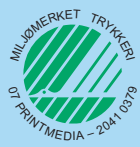

Printed in Norway

www.norden.org/nordpub

\section{Nordic co-operation}

Nordic co-operation is one of the world's most extensive forms of regional collaboration, involving Denmark, Finland, Iceland, Norway, Sweden, and the Faroe Islands, Greenland, and Åland. Nordic co-operation has firm traditions in politics, the economy, and culture. It plays an important role in European and international collaboration, and aims at creating a strong Nordic community in a strong Europe. Nordic co-operation seeks to safeguard Nordic and regional interests and principles in the global community. Common Nordic values help the region solidify its position as one of the world's most innovative and competitive.

Nordic Council of Ministers

Ved Stranden 18

DK-1061 Copenhagen K

Phone (+45) 33960200

www.norden.org 


\section{The Norwegian Presidency of the Nordic Council of Ministers 2017}

\section{Contents}

Preface 4

The Nordic Region in Transition 6

The Nordic Region in Europe $\quad 14$

The Nordic Region in the World 16 


\section{Greetings from the Prime Minister and the Minister for Nordic Co-operation}

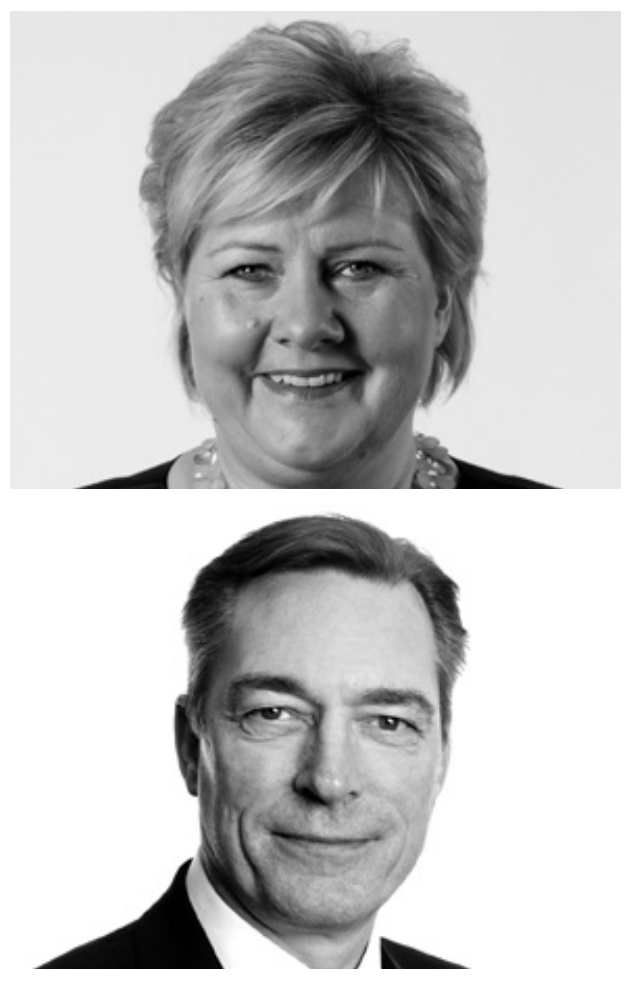

Prime Minister

Erna Solberg

Minister for Nordic Co-operation Frank Bakke-Jensen 
The Nordic region, the climate and our demographics are all changing, and major economic and environmental restructuring will be needed to cope with the situation. Global trends are accelerating, in both positive and negative directions, in an increasingly volatile and dynamic world.

Everyday life is changing, and the choices we make now will affect both our own and future generations. The greatest danger is that we are too slow to adapt to the world around us, to changes in technology, the economy and the makeup of our populations.

During the 2017 Presidency, we want to improve the Nordic region's ability to face up to these changes. Nordic cultural affinity and shared values and interests provide a unique foundation from which to tackle these challenges and influence global developments.

The Nordic Region in Transition pillar of the programme for the Presidency will promote competitiveness during the transition to a green, low-emission economy. The Paris Agreement sets ambitious targets, to be achieved in a European framework. When aiming at the targets set for 2030 and 2050, the ambition is for the Nordic countries to lead the way by working together on climate and environmental issues and improving competitiveness, growth and our welfare model. Working even more closely together on education, research and innovation will allow us to develop our comparative advantages, and ensure that the Nordic region plays a key role in the global transition to a green economy. We will pioneer new ways of responding to demographic changes in age, health and the way we integrate and include newcomers.

The Nordic Region in Europe pillar of the programme is designed to facilitate closer co-operation on European policy. A strong Nordic voice in Europe is good for the region and good for Europe. The Nordic region needs a strong Europe. Europe needs a strong Nordic region. Nordic precedents can provide inspiration on the climate and the environment, on energy issues, digitisation and other areas of mutual interest. Membership of the EU and EEA means that the Nordic countries share a fundamental interest in the future of the internal market. The Nordic region must continue to be one of the most integrated and competitive economies in Europe, with a high degree of mobility and co-operation between the countries.

The Nordic Region in the World pillar will further develop our foreign policy partnership in order to meet the big global challenges. The Nordic countries have a long-standing history of working together on foreign affairs and enjoy a positive reputation. This means that we are able to exert influence. What happens in the world impacts on the Nordic region faster than ever before. Change is more immediate, and the region is best served by strategic global commitment.

The Norwegian Presidency 2017 is based on these three pillars. We look forward to working with you on them. 


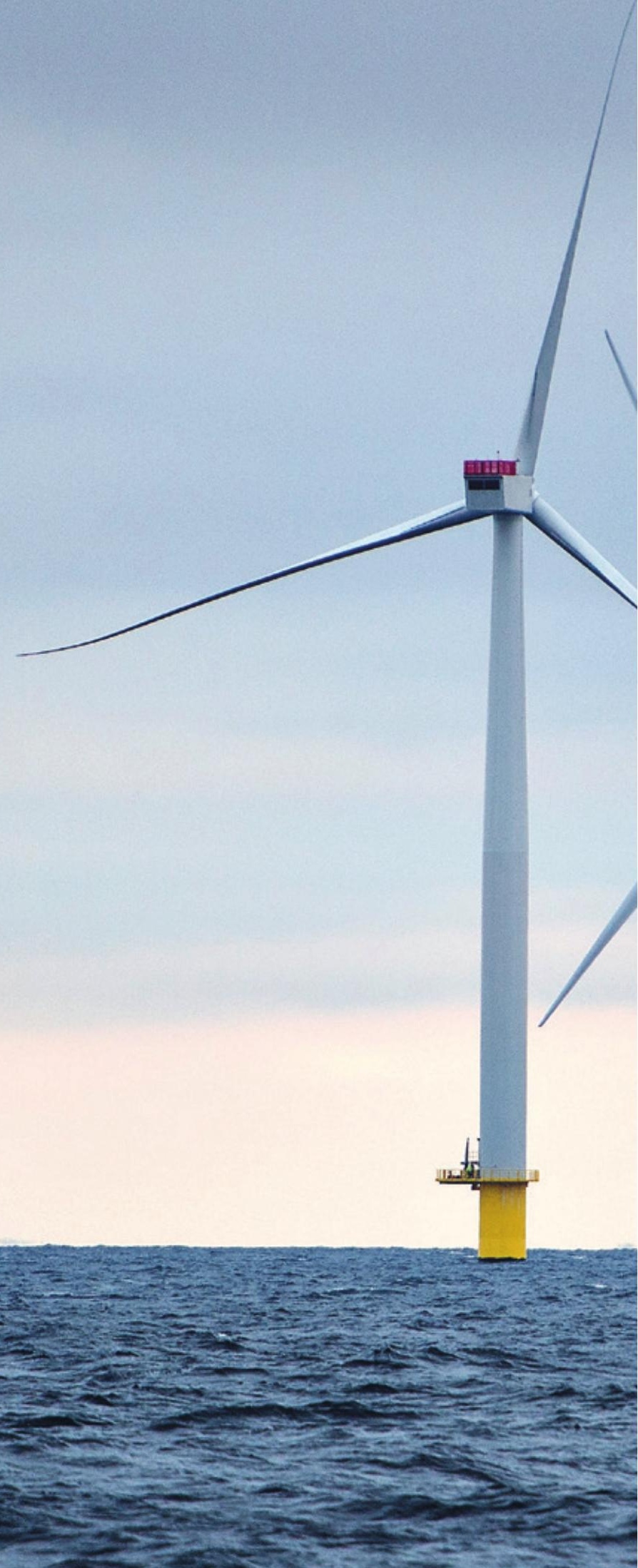




\section{The Nordic Region in Transition}

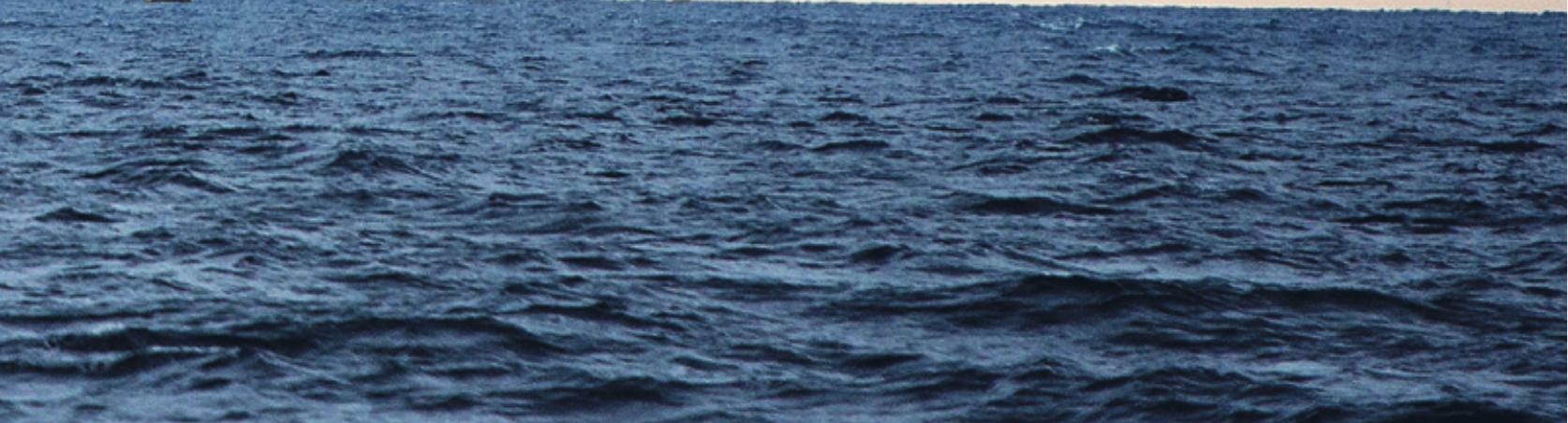




\section{Economy and climate - green transition}

The Nordic region faces a tough process of economic transition over the next few decades. Global climate and environmental challenges require a global green transition, and the Paris Agreement lays the foundation for wide-ranging changes. In Europe, the USA and China, the pace of transition is accelerating, as increasingly competitive climate-oriented and environmentally friendly solutions emerge from dynamic interactions between research and development, more stringent policies, digitisation and new trends and patterns of consumption. The Nordic region needs more diversified business and industry to remain competitive in the new, green, global economy. This is why green transition plays such a prominent role in the programme for the Norwegian Presidency of the Nordic Council of Ministers in 2017.

Levels of optimism about the future are high in the Nordic region. Our countries top the international rankings for welfare and quality of life. The Nordic model of high employment, mutual trust between unions and employers, and a well-developed welfare state has proved robust and adaptable in the face of globalisation. We have all of the prerequisites for a successful conversion process.

The region is also one of the most highly skilled, innovative and attractive regions in the world. Collectively, our economy ranks 10-12th in the world, and is one of the most well integrated. We are each other's main trading partners, work together on research and innovation and enjoy a high degree of mobility in the Nordic labour market and education area. We need to work even more closely together, promote even greater freedom of movement, and intensify efforts to prevent and remove existing obstacles to Nordic growth.

A range of processes already underway, combined with new initiatives, will enhance the Nordic work on green transition in 2017.

- The Nordic institutions NordForsk, Nordic Innovation and Nordic Energy Research will launch the Nordic Green Growth Research and Innovation Programme, which is designed to fund the best Nordic research and innovation projects dealing with the green transition. The programme has a budget of NOK 73 million. The objectives include sustainable development, reducing industry's impact on the climate, boosting Nordic competitiveness in international markets for green technologies, goods and services, and developing new knowledge and policies.

- A strategic review of the environmental sector will evaluate the potential for the Nordic countries to work more closely together on climate and environmental issues. A similar analysis of energy 
co-operation is already being conducted (the Ollila Report).

- The content of the new Nordic Co-operation Programme for Innovation and Business Policy 2018-2021 will be finalised during the Norwegian Presidency, setting new targets for co-operation on green transition.

- The new Nordic Co-operation programme for Regional Development and Planning 2017-2020, which seeks to stimulate innovative regional business environments, will be launched during the Presidency.

- Urbanisation is one of the key challenges the Nordic region faces in its transition to a green economy. A project on green transition and competitiveness in Nordic urban regions will help to make Nordic towns and cities part of the solution to environmental and climate challenges. The project is designed to identify indicators for attractiveness, and determine how the quality of cities affects the environment, public health and the creation of attractive jobs.

- The project on the marine environment and the blue bioeconomy will highlight the role of "the blue forests" in the carbon cycle and in the marine ecosystem. It will also map concentrations of plastic microbeads in selected Nordic species, and assess the potential impact of these and other kinds of marine plastic litter on blue bio-industries. In addition, the project will seek to combat illegal fishing and the spread of invasive Pacific oysters.
- The green bioeconomy project will promote greater sustainability in agriculture by making more effective use of residual materials and waste and cutting down on waste in supply chains and by consumers.

- The Nordic Genetic Resource Center (NordGen) and the Svalbard Global Seed Vault are central to the bioeconomy and to future food production. The Norwegian Presidency will intensify work on the sustainable use of genetic resources.

- We will continue Nordic co-operation on reducing greenhouse gas emissions from agriculture, increasing carbon capture in forests and in the soil and adapting industry to a changing climate.

The Freedom of Movement Council is a politically appointed body with a remit from the Nordic governments to promote mobility in the region for people and for business. As part of the efforts to convert the Nordic economy and make it more competitive, the work on freedom of movement will be a top priority for the Norwegian Presidency. Removing barriers to freedom of movement creates jobs, improves competitiveness and contributes to growth. 


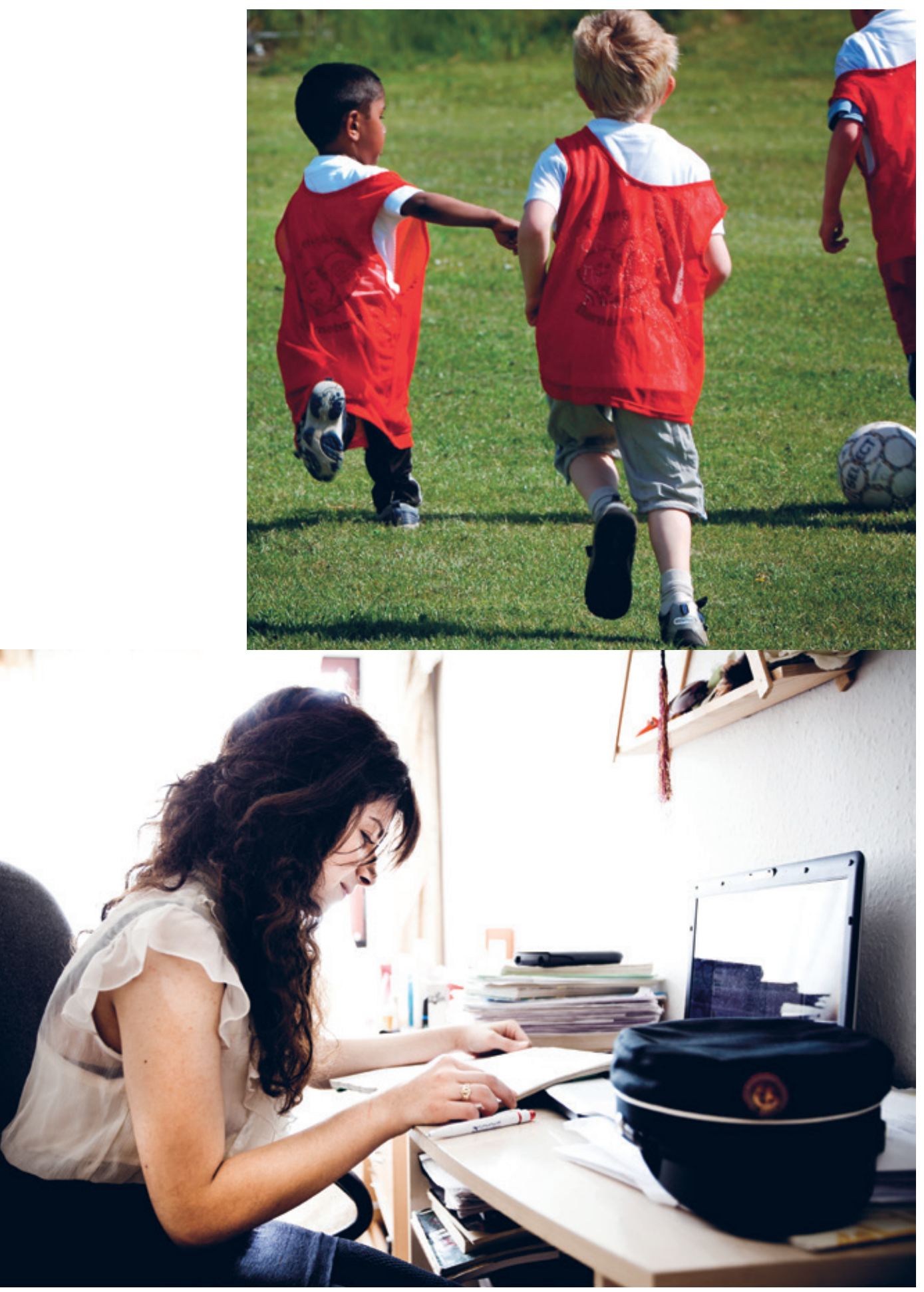




\section{Demographic changes - integration and inclusion}

Developments in Europe in recent years have shown that migration and integration are among the major political, social and economic challenges of our age. Ensuring the successful integration and inclusion of new members of Nordic society is not just a basic human responsibility, but an economic and social necessity. Our Nordic societies face major challenges in this area, but are also in a unique position to succeed and to show the way to other countries in Europe and beyond.

The Norwegian Presidency will initiate a broad programme of co-operation on integration, with an emphasis on the development and exchange of knowledge and practice. Norway is in favour of additional Nordic initiatives promoting integration.

A project on the role of culture and volunteers in work on integration and inclusion will help to open up Nordic communities to new arrivals. In many local communities and local authorities, culture, sport, associations and organisations are the most important venues where people congregate outside of work and education. Making these spheres accessible and inclusive provides immigrants with vital opportunities to meet people in their local community, learn and practice their new language, share resources and develop a sense of belonging.

A project in the education and research sector will identify and develop effective models for recognising educational and vocational qualifications from other countries. A clearer overview of the schemes used in the Nordic countries to compare qualifications will help to speed up and improve integration. Coordinating the national systems where appropriate will also ensure more efficient use of resources.

A three-year, intersectoral project that focuses on vulnerable children and young people will seek tangible solutions to the increasing challenges faced by local authorities throughout the region with regard to education, employment, health care, child welfare, housing and integration.

Work, education and language will be highlighted as the key to successful integration and new wealth creation, as well as for preventing exclusion and radicalisation. Norway will continue work on the project promoting democracy, inclusion and security, which aims to enhance the role of the school as the centre of inclusion and active citizenship. 


\section{Health}

The Norwegian Presidency will base its approach to health on the recommendations in the strategic review of Nordic co-operation on health (the Könberg Report).

- We will launch a project to increase knowledge of antibiotic resistance and draw up a Nordic communications plan to reduce the use of them. Antibiotic resistance is a rapidly growing problem and a serious threat to global health.

- A Nordic project on health data and clinical intervention studies will seek to speed up the process of identifying the causes of disease and to develop more personalised prevention and treatment in health and care services. Several clinical studies and comparative registry studies at Nordic level will boost competitiveness in a knowledgebased economy.

- In 2017, we will study the harmonisation of ethical approval of Nordic research projects. Harmonisation will lead to major savings in terms of time and resources, and make the Nordic region more competitive. This will support the implementation of the new EU directive on clinical trials of medicinal products for human use, as well as Nordic co-operation on health research.

- We will also study the potential for a Nordic virtual centre for research into health data. The long-term aim is an electronic infrastructure that will make it easier to exchange health data between the Nordic countries. 


\section{The Nordic Region in Europe}

- closer collaboration on European policy

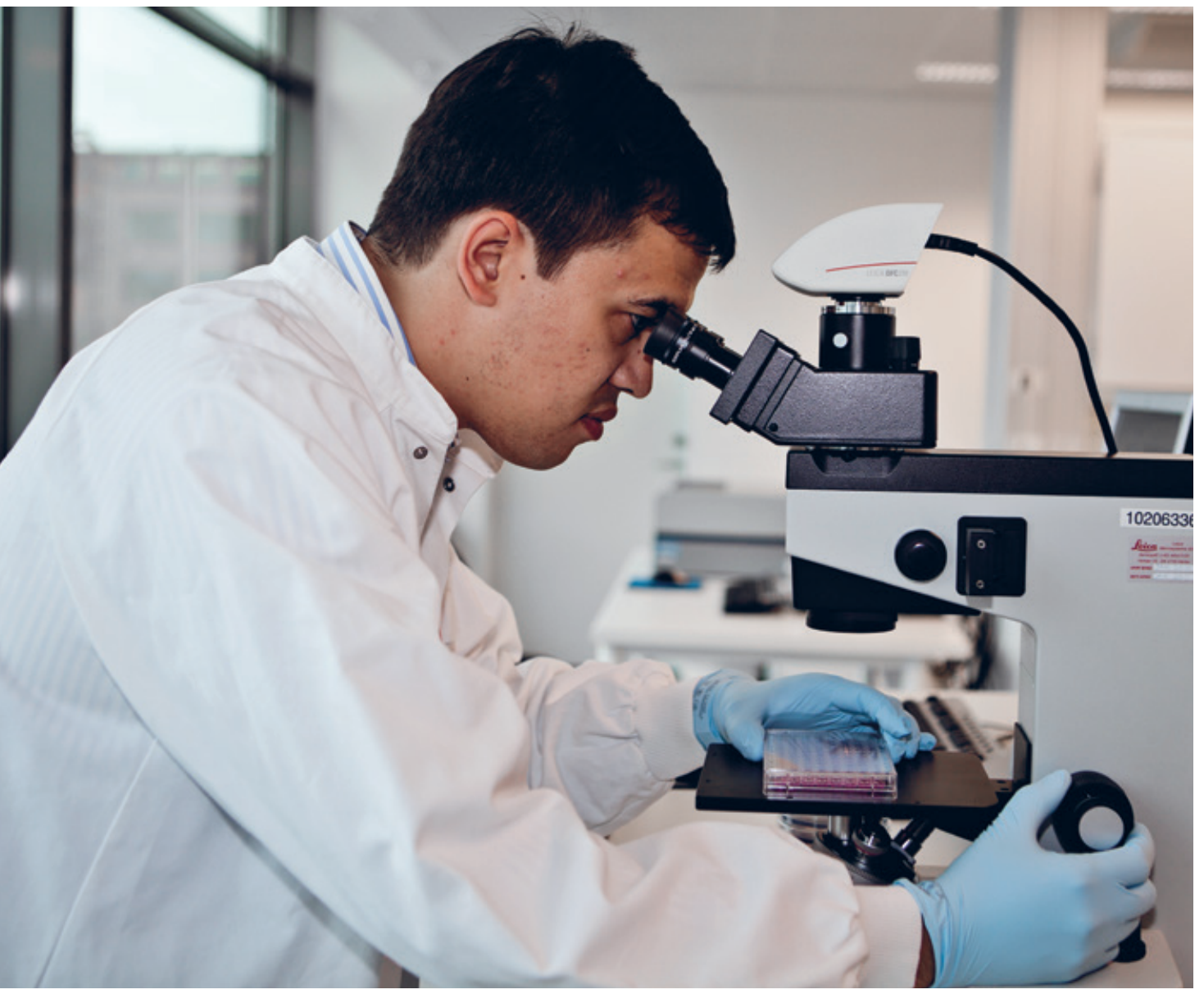


The Nordic region is part of Europe. Membership of the EU and the EEA shapes everyday life in the region, and allows us to inspire and exert influence on the continent.

Co-operation at European level is subject to constant pressures. Economic growth is uneven. Youth unemployment is too high. The challenges of migration persist. Doubts are increasingly expressed about democratic values, European society is becoming increasingly polarised and the security situation has changed.

Europe's challenges are our challenges, and co-operation at European level is our most fundamental foreign policy and economic interest. The inner market is crucial for our economies. Closer European political co-operation will promote economic integration and freedom of movement and prevent barriers to growth in the Nordic region.

We will defend the concept of Europe and support the forces that favour closer ties throughout the continent. We will be a strong supporter of a Europe that defends liberal values and human rights, and takes responsibility for its own security. We are better able to pursue Nordic interests when our views become European views. The Nordic region can help ensure that Europe continues to lead the way, as the EU currently does, on issues such as climate policy.

Recent years have seen the Nordic countries work more and more closely with each other on European policy. Norway will continue the work started by the Finnish Presidency on prioritising
Nordic co-operation on European policies. In 2017, we will prioritise work on greater Nordic visibility in Brussels and more Nordic input in areas of joint interest.

In terms of themes, we will focus on three areas of strategic interest for the Nordic countries, in which the region is - and should be - at the forefront: energy, climate and the environment, and digitisation.

The Norwegian Presidency will draw up a new action plan for Nordic energy policy co-operation 2018-2021 based, among other things, on a strategic review (the Ollila Report). Our ambition is for the region to continue to serve as a source of inspiration for progress toward the Energy Union and the European electricity market, and that the Nordic countries will work more closely together on European regulation. Energy co-operation also includes tangible joint work on research and development within the framework of Nordic Energy Research (NEF).

In our work on climate and environment, we will seek to ensure that Nordic co-operation contributes to an ambitious and effective European climate policy in line with the objectives of the Paris Agreement. We will also seek to ensure that Nordic co-operation makes a substantial contribution to cutting emissions.

Digitisation is one of the keys to European competitiveness. The Nordic region needs to be a competent, innovative, dynamic region for the development of digital products, services and knowledge. We will contribute to policy development in the EU and build on existing Nordic collaboration in this sphere. 


\section{The Nordic Region in the World}

- a strategic Nordic partnership in foreign policy

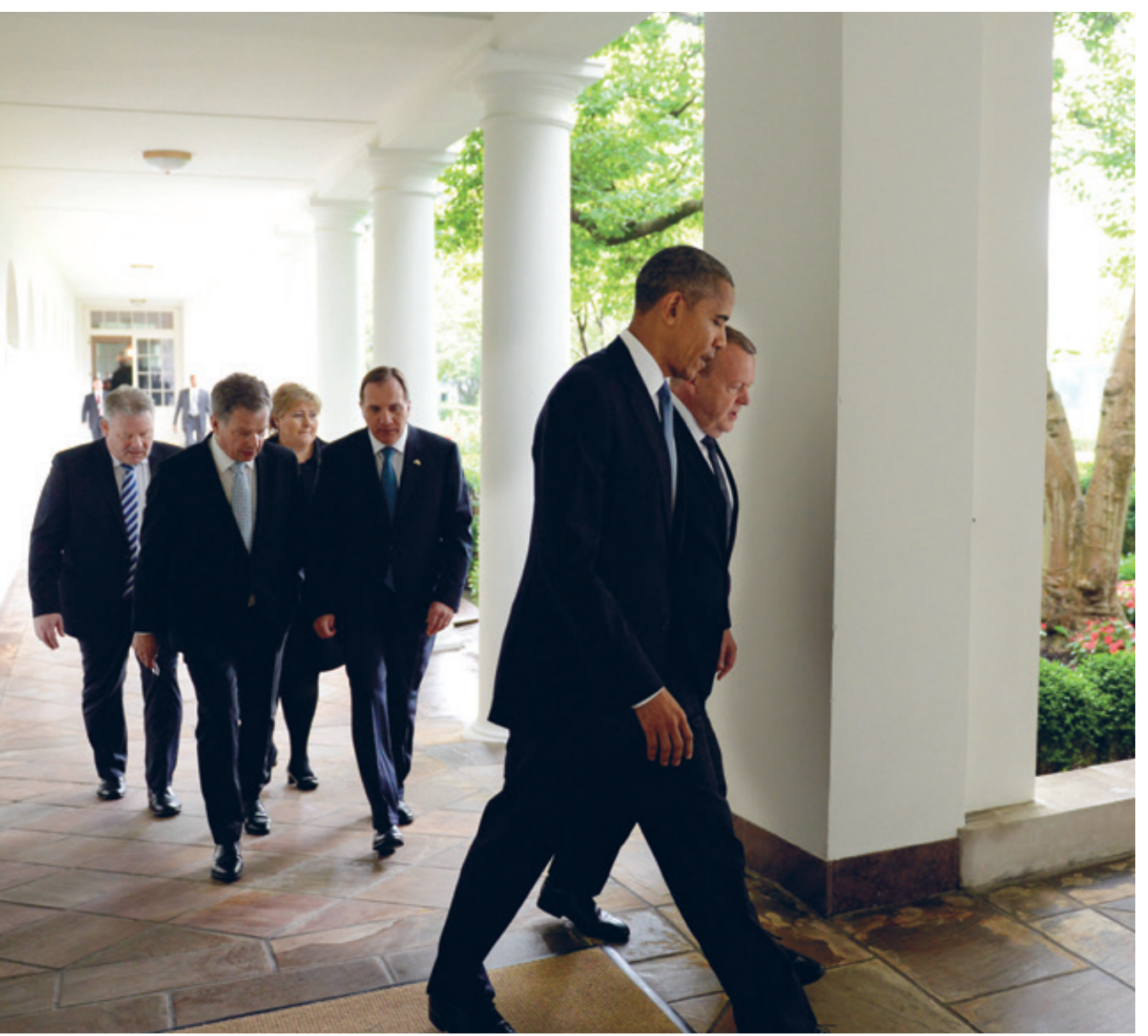


The Nordic countries share fundamental values and interests. International issues have been affecting everyday Nordic life more directly than ever in recent years. Crises seem to be getting closer. War and conflict to the south and east of the Mediterranean have direct consequences for the security of the European continent. States in North Africa and the Middle East are collapsing. Livelihoods are disappearing. People are being forced to flee. States have become havens for terror groups. Freedom of expression is under pressure. Openness is threatened by protectionism and nationalism. International law is being challenged.

The world is getting smaller. Global events impact upon the Nordic region more and more quickly, and the world needs a strategic Nordic region.

There are also positive trends: global poverty is being reduced, we have a new and ambitious climate agreement, more children are receiving education and better health care, and economic growth continues in both Asia and Africa. We will work to safeguard and develop the common good at global level, especially via the United Nations, where we will continue to present a committed Nordic voice. We also want the Nordic region to continue to be a preferred partner in important processes in the global arena.

The Nordic Council of Ministers' international work complements informal Nordic dialogue on foreign and security policy, and yields mutual synergies and benefits. This is a natural consequence of the blurring of boundaries between domestic and foreign policy. We will strive to make the integration between formal and informal Nordic co-operation on foreign policy even more seamless.

This will require Nordic knowledge and understanding of trends in international politics and economics. In 2017, Norway will continue to develop co-operation between the Nordic foreign policy institutes by supporting joint research

The purpose of the prime ministers' initiative is to promote Nordic input that will help meet international demand for innovative social solutions in areas of Nordic expertise. The priority themes are "Nordic Green", "Nordic Food and Welfare", and "Nordic Gender Effect". The initiative has a budget of DKK 30 million over three years. It will also receive funds from Nordic Innovation and other Nordic institutions. 
projects and conferences. This work will contribute to even closer co-operation on foreign policy and draw attention to the region in foreign policy debates.

We want the Nordic region to be more visible and recognisable. By working together, we reach more people and bigger markets, and are able to satisfy the steadily growing demand for Nordic art and culture. Throughout 2017, London's Southbank Centre will host a Nordic culture festival showcasing a wide range of Nordic arts and culture.

The work on "Brand Norden" will help boost the region's profile when Nordic bodies and companies are promoting their interests abroad. The close co-operation between embassies, particularly in countries where the Nordic embassies are all on the same site, generates considerable added value in terms of raising the profile of the region and facilitating co-operation on foreign policy.
Working with neighbouring countries and regions plays a special role in Nordic co-operation. In 2016, the Council of Ministers' Information Offices in the Baltic republics celebrated their quartercentury. Nowadays, the partnership with the Baltic countries is based on common interests - as highlighted by the current security situation. The Council of Ministers will continue to be an important partner for Estonia, Latvia and Lithuania, supporting them on issues like free and independent media, culture and energy security. The Nordplus programme seeks to enhance mobility between Nordic and Baltic educational institutions. EEA funding is another important means of providing support for joint Nordic interests in the Baltic states. We will use it to set up tangible forms of co-operation on foreign policy with the Baltic states in areas that will promote regional stability and development. 
New Nordic Region 2.0

New Nordic Region 2.0 is a reform process designed to improve the flexibility and effectiveness of the Nordic Council of Ministers and to free up resources for immediate political priorities. Following a recommendation by the Secretary General of the Council of Ministers, the ministers for Nordic co-operation have adopted the following goals for the reform process:

1. Make the Nordic region the most well-integrated region in the world.

2. Ensure that Nordic co-operation contributes to sustainable growth in the region.

3. Enhance the relevance of Nordic co-operation to the people of the region.

4. Devise a more dynamic form of Nordic budgeting.

5. Adjust the structure of the Council of Ministers.

6. Use ad hoc meetings to achieve greater topicality and set up an ad hoc council of ministers for integration questions.

7. Improve interaction between ministers and civil servants.

8. Make co-operation between civil servants more dynamic.

9. Increase Nordic co-operation both within and outside of the Council of Ministers.

10. Ensure that the prime ministers set the overall direction for Nordic co-operation.

11. Enhance the analytical capabilities of the Nordic Council of Ministers' Secretariat. 


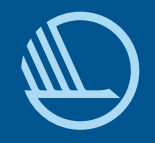

Nordic Council of Ministers

Ved Stranden 18

DK-1061 Copenhagen K

www.norden.org 